\title{
FORMULASI HAND \& BODY LOTION ANTIOKSIDAN EKSTRAK LULUR TRADISIONAL
}

\author{
Nutrisia Aquariushinta Sayuti, Indarto AS, Suhendriyo \\ Kementerian Kesehatan Politeknik Kesehatan Surakarta Jurusan Jamu
}

\begin{abstract}
Scrub, Lotion, Antioxidants. Turmeric (Curcuma domestica L), Temu giring (Curcuma heyneana), cinnamon bark (Cinnamomum Bumani (nees) BI), Kemuning Leaf (Murraya paniculata (L) Jack) and sandalwood (Santalum album) was often combined in the manufacture of scrubs. This research aims to make Hand \& Body lotion formula ( $H \& B$ Lotion) antioxidant containing traditional herbal extract from the botanicals fifth practical that efficacious, stable, safe and preferred by consumers. This research was true experimental research. The antioxidant activity test was used the immersion method against free radical diphenyl -2-1.1 picrylhydrazyl, the protection ability test using invitro test while irritation test and hedonic tests conducted on volunteers. Emulsions that tested were containing traditional herbal extract with a concentration of $0.5 \%, 1.0 \%$ and $1.5 \%$. This study concluded that the $H \& B$ Lotion was stable with emulsifier concentrations of 4.5\% Tween 80, the difference in concentration of the extract didn't affect the protection ability and the safety of the product but it effect significantly on the efficacy of antioxidants and aroma sensory parameters on hedonic test's results, Optimal antioxidant activity in traditional herbal extract concentration of 1.5\%. The best products based assessment hedonic test was $H \& B$ lotion with extract content of $1.0 \%$
\end{abstract}

Keywords: Scrub, Lotion, Antioxidants

Abstrak : Lulur, Lotion, Antioksidan. Kunyit (Curcuma domestica L), temu giring (Curcuma heyneana), kulit kayu manis (Cinnamomum Bumani (nees) BI), Daun Kemuning (Murraya paniculata (L) Jack) dan kayu cendana (Santalum album) adalah simplisia yang paling sering dikombinasikan dalam pembuatan lulur. Penelitian ini bertujuan membuat formula Hand \& Body lotion (H\&B Lotion) antioksidan yang mengandung ekstrak lulur tradisional yang terbuat dari kelima simplisia tersebut sehingga stabil, berkhasiat, aman dan disukai konsumen. Penelitian ini merupakan penelitian true eksperimental. Uji aktivitas antioksidan dari emulsi menggunakan metode perendaman terhadap radikal bebas 1,1 difenil -2- pikrilhidrazil, uji daya proteksi invitro sedangkan uji iritasi dan uji hedonic dilakukan terhadap sukarelawan. Emulsi yang diuji mengandung ekstrak lulur tradisional dengan konsentrasi $0,5 \%$, $1,0 \%$ dan $1,5 \%$. Dari hasil penelitian dapat disimpulkan bahwa H\&B Lotion stabil dengan emulgator Tween 80 konsentrasi 4,5\%, Perbedaan konsentrasi ekstrak tidak berpengaruh terhadap daya proteksi dan keamanan dari produk tetapi berpengaruh nyata terhadap khasiat antioksidan dan parameter sensori aroma pada hasil uji hedonic. Aktivitas antioksidan optimal pada konsentrasi ekstrak lulur tradisional 1,5\%. Produk terbaik berdasarkan penilaian uji hedonic adalah H\&B Lotion dengan kandungan ekstrak $1,0 \%$ 
Kata Kunci : Lulur, Lotion, Antioksidan

\section{PENDAHULUAN :}

Trend back to nature yang tengah melanda dunia estetika meningkatkan penelitian terhadap formula kosmetika dan juga terhadap beberapa tanaman sebagai bahan aktif kosmetika. Penelitian tersebut dilakukan terhadap tanaman yang sudah digunakan secara turun temurun mau pun penelitian yang bertujuan mencari tanaman baru sebagai inovasi dan variasi bahan aktif. Peningkatan penelitian formula kosmetika juga bertujuan untuk mencari bentuk sediaan kosmetika yang tahan lama, praktis, mudah dan cepat diaplikasikan yang sudah menjadi kebutuhan manusia modern dalam kehidupan yang serba cepat. Terdapat banyak sediaan kosmetika tradisional yang salah satunya adalah lulur. Lulur ditumbuk atau digiling, dibuat pasta, lalu dioleskan di atas kulit dan digosok untuk mengangkat sel kulit mati (Felicia.N, 2011). Cara aplikasi tersebut dinilai kurang praktis sehingga dikembangkan produk kosmetika yang pengaplikasiannya juga ke seluruh tubuh, sama dengan lulur yaitu hand and body lotion $(\mathrm{H} \& \mathrm{~B}$ Lotion).

H \& B Lotion biasanya berbentuk emulsi karena penampakannya menarik serta mempunyai konsistensi menyenangkan. Emulsi dibuat dari campuran minyak, air dan emulgator sebagai basis emulsi serta penambahan ekstrak tanaman sebagai bahan aktif. Penelitian terhadap formula emulsi biasanya dilakukan percobaan terhadap basis emulsi dahulu dengan dibuat beberapa formula basis dengan variasi konsentrasi minyak atau variasi konsentrasi emulgator yang berbeda-beda kemudian masing-masing formula diuji stabilitas fisiknya. Untuk uji khasiat dilakukan penambahan bahan aktif pada basis yang paling stabil, sama seperti pengujian basis, dibuat beberapa formula dengan variasi konsentrasi bahan aktif.

Emulgator yang paling sering adalah Tween 80. Sebagai surfaktan biasanya, Tween 80 digunakan dengan konsentrasi $1-15 \%$. Zat tersebut berangsur-angsur akan tersaponifikasi dengan asam kuat dan basa. Percobaan terhadap Tween 80 dilakukan dengan merubah-rubah konsentrasinya dalam emulsi untuk diuji kestabilan emulsi yang dihasilkan. Tujuan percobaan tersebut adalah untuk mengetahui konsentrasi Tween 80 optimal yang menghasilkan emulsi yang stabil dalam penyimpanan (Anonim,1995, Rowe, Raymond C, dkk. 2009)

Kelemahan penggunaan tanaman secara tradisonal adalah tidak praktis, tidak stabil dalam penyimpanan dan zat warna kuning dari Curcumin sering kali menempel di beberapa tempat yang tidak dikehendaki sehingga sukar dibersihkan. Dengan mengekstrak serbuk kering tanaman tersebut dan dicampur dengan basis emulsi dapat mengurangi masalah diatas. Masing-masing tanaman dibuat simplisia, diserbuk kemudian diekstraksi secara macerasi dengan penyari ethanol 95\%. Keempat ekstrak yang didapat, dikombinasikan dan selanjutnya dalam penelitian ini disebut ekstrak lulur tradisional. Ekstrak lulur tradisional inilah yang menjadi bahan aktif dalam emulsi dengan khasiat sebagai antioksidan. 
Perkembangan bentuk emulsi praktis memang diperlukan namun, perkembangan tersebut belum tentu mendukung khasiat antioksidan dari ekstrak lulur tradisional, keamanan dan juga penerimaan konsumen terhadap produk yang dihasilkan. Penelitian terhadap khasiat antioksidan ekstrak lulur tradisional setelah dibentuk emulsi juga tetap harus dilakukan terutama untuk mengetahui kosentrasi optimal dari eksrak yang menghasilkan daya antioksidan maksimal. Penambahan bahan lain sebagai basis emulsi membuat keamanan sediaan dipertanyakan kembali. Oleh karena itu penelitian ini tidak hanya untuk mengetahui stabilitas fisik dari emulsi yang dihasilkan tetapi juga menguji aktivitas antioksidannya, daya proteksi, keamanannya dengan uji iritasi serta menguji penerimaan konsumen dengan uji hedonik.

\section{METODE PENELITIAN}

Penelitian ini adalah penelitian true eksperimental. Sampel rimpang kunyit, temu giring, daun kemuning, kulit kayu manis dan kayu cendana dibuat ekstrak ethanol secara maserasi. Kelima ekstrak tersebut dicampur dengan konsentrasi sama banyak yang selanjutnya dalam penelitian ini dinamakan ekstrak lulur tradisional. Ekstrak lulur tradisional ditambahkan pada basis emulsi pembentuk $\mathrm{H} \& \mathrm{~B}$ Lotion dengan variasi konsentrasi $\quad 0,5 \%$ (Formula A), 1,0\% (Formula B) dan 1,5\% (Formula C) kemudian dilakukan uji aktivitas antioksidan, uji iritasi, uji daya proteksi dan uji hedonic. Populasi yang digunakan dalam uji iritasi dan uji hedonic adalah mahasiswi Jurusan Jamu Poltekkes Surakarta tahun ajaran 2014/2015. Sampel yang digunakan untuk uji hedonik adalah
19 orang mahasiswi semester 4 dan 6 Jurusan Jamu yang berfungsi sebagai panelis. Sedangkan sampel yang digunakan uji iritasi adalah 15 orang mahasiswa yang berfungsi sebagai sukarelawan. Jumlah sukarelawan disesuaikan dengan uji iritasi yang telah dilakukan oleh Rao, dkk, 2008 yang menyatakan bahwa sukarelawan yang digunakan adalah 3 orang untuk masingmasing bahan uji. Dalam penelitian ini dilakukan uji iritasi terhadap salah satu brand $\mathrm{H} \& \mathrm{~B}$ lotion yang sudah beredar di pasaran, basis emulsi dan 3 emulsi yang masing-masing mengandung ekstrak lulur tradisional $0,5 \%, 1,0 \%$ dan $1,5 \%$.

Kriteria penerimaan: Relawan yang berpartisipasi dalam pengujian ini adalah wanita berusia 19-21 tahun dalam keadaan sehat dan mempunyai kulit normal dan/ atau sensitif. Sebelum pengujian berlangsung, relawan menandatangani form "pernyataan kesediaan menjadi sukarelawan" terlebih dahulu. Relawan juga harus menghentikan pemakaian produk lain pada daerah uji selain produk yang diuji, satu minggu sebelum dan selama pengujian berlangsung. Kriteria. Penolakan: Relawan dengan masalah kesehatan, wanita hamil dan sedang menyusui, dan/ atau mereka yang sedang menggunakan obat yang dapat mempengaruhi keadaan kulit sehingga dapat mengganggu pengamatan

\section{HASIL PENELITIAN}

Masing-masing simplisia penyusun ekstrak lulur tradisional yang terdiri dari simplisia Kunyit, Temu giring, kayu cendana, Daun Kemuning, dan kulit kayu manis, ditimbang \pm 2500 gram, diserbuk dengan cara diblender kemudian diayak dengan mesh no. 40. Penetapan kadar air 
serbuk simplisia dilakukan dengan metode oven kering dan didapatkan kadar air dari serbuk simplisia kunyit, temu giring, kayu cendana, daun kemuning dan kulit kayu manis masing-masing 5,51\%, $6,65 \%, 1,67 \%, 8,06 \%$ dan $6,19 \%$.

Kelima serbuk simplisia tersebut kemudian diekstraksi dengan penyari ethanol 95\% secara maserasi. Maserasi dilakukan dengan replikasi sebanyak tiga kali dan masing-masing replikasi menggunakan serbuk simplisia seberat 50,0 gram. Hasil dari rendemen ekstraksi kunyit adalah $16,10 \%$, rendemen ekstrak Temu giring adalah $14,32 \%$, rendemen ekstrak kayu cendana 14,32\%, ekstrak daun kemuning $21,32 \%$ dan ekstrak kulit kayu manis sebesar 16,87\%. Hasil tes ekstrak sudah bebas dari pelarutnya yaitu ethanol $95 \%$ yang ditunjukkkan dengan tidak terbentuknya bau ester yang khas dari alkohol pada uji esterifikasi. Kelima ekstrak yang dihasilkan dicampur dengan konsentrasi sama banyak.

Dalam penelitian formulasi basis emulsi yang akan digunakan dalam $\mathrm{H} \& \mathrm{~B}$ Lotion, peneliti membandingkan stabilitas 3 formula basis emulsi dengan perbedaan konsentrasi Tween 80 untuk masingmasing formula, yaitu $1,5 \%$ untuk formula I, 3,0\% untuk Formula II dan 4,5\% untuk Formula III. Bahan tambahan lain yang digunakan dalam ketiga formula adalah ekstrak lulur tradisional $0,5 \%$, minyak mineral $10 \%$, minyak zaitun $5 \%$, asam stearat $2 \%$, Propilenglikol 15\%, malam putih 1,5\%, cethyl alcohol, 1,5\%, Propilparaben $0,1 \%, \mathrm{KOH} 0,2 \%$, Sorbitol $5 \%$, Natrium Citrat $0,1 \%$, polyvinyl Pirolidon 0,5\%, Oleum Cananga 0,2\% dan Aquadest sampai $100 \%$. Masing-masing formula dibuat 300 gram dengan replikasi 3 kali. Hasil dari formula dilakukan uji stabilitas dengan cara pengamatan organoleptik, homogenitas, $\mathrm{pH}$ dan viskositas, dilakukan dalam kondisi dipaksakan (stressed condition) untuk mempercepat peruraian dan mengurangi waktu yang diperlukan untuk pengujian. Penyimpanan kondisi dipercepat dilakukan pada suhu antara 5 dan $35^{\circ} \mathrm{C}$ masing-masing 12 jam selama 10 siklus. Sediaan emulsi dinyatakan stabil bila tidak terdapat perubahan yang signifikan pada hasil parameter yang diamati. Uji tipe emulsi dan derajat pemisahan fase dilakukan pada suhu kamar selama 28 hari.

Formula dengan stabilitas fisik terbaik kemudian dipilih sebagai basis emulsi yang digunakan dalam sediaan $\mathrm{H} \& \mathrm{~B}$ Lotion antioksidan. Basis tersebut dibuat 3 formula dengan perbedaan konsentrasi ekstrak lulur tradisional tiap formula yaitu $0,5 \%$ untuk Formula A, $1,0 \%$ untuk Formula B dan 1,5\% untuk Formula C. Masing-masing formula dibuat 3 botol dengan volume $100 \mathrm{ml} /$ botol yang selanjutnya dilakukan uji aktivitas antioksidan dengan peredaman radikal bebas 1,1 difenil -2- pikrilhidrazil $(\mathrm{DPPH})$ sesuai yang dilakukan Simanjuntak et al, (2011), uji iritasi yang dilakukan pada sukarelawan selama 72 hari, uji daya proteksi secara invitro dan uji hedonik.

\section{PEMBAHASAN}

Hasil t-test terhadap viscositas basis emulsi, tidak terdapat perbedaan viscositas sebelum dan sesudah penyimpanan dengan kondisi dipaksakan pada emulsi formula III yang ditunjukan dari harga $p$ value $>0,05$ sehingga terdapat kestabilan viscositas pada sediaan emulsi formula III sedangkan pengujian terhadap $\mathrm{pH}$ formula basis emulsi menunjukkan bahwa tidak terdapat 
perbedaan $\mathrm{pH}$ sebelum dan sesudah penyimpanan dengan kondisi dipaksakan pada emulsi formula I, II dan III yang ditunjukan dari harga $p$ value $>0,05$ sehingga terdapat kestabilan $\mathrm{pH}$ pada setiap formula sediaan emulsi.

Dari hasil uji anava dua arah yang dilakukan terhadap hasil uji viskositas dan pH dapat disimpulkan bahwa konsentrasi Tween 80 berpengaruh terhadap viscositas dan $\mathrm{pH}$ sediaan. Hasil Tuckey Test terhadap viscositas basis emulsi menunjukkan bahwa tidak ada perbedaan antara formula I dan II (p-value 0,309) dan ada perbedaan antara formula I dan III (p-value 0,002) dan antara formula II dan III (p-value 0,037), sedangkan hasil Tuckey test pada $\mathrm{pH}$ basis emulsi menunjukkan data tidak ada perbedaan antara formula I dan II (p-value 0,261) dan antara formula I dan III (pvalue $=0,060)$, perbedaan signifikan terdapat antara $\mathrm{pH}$ formula II dan III (pvalue 0,003 ).

$\begin{array}{lrr}\text { Dalam } & \text { formula, Kalium } \\ \text { Hidroksida sebagai basa }\end{array}$ mempengaruhi $\mathrm{pH}$ emulsi sehingga perlu ditambahkan zat pendapar, dalam hal ini adalah Natrium Citrat agar $\mathrm{pH}$ emulsi memenuhi syarat keamanan $\mathrm{pH}$ produk kulit yaitu 4,5 s.d 6,5 (Tranggono dan Latifa, 2007). Menurut Rahmanto, 2011, kulit yang memiliki pH 5,0 - 6,5 dapat beradaptasi dengan baik saat berinteraksi dengan bahan yang memiliki $\mathrm{pH} 4,5-8,0$ (SNI, 1996). $\mathrm{pH}$ sediaan harus disesuaikan dengan $\mathrm{pH}$ kulit karena jika tidak sesuai dengan $\mathrm{pH}$ kulit, sediaan tersebut beresiko mengiritasi kulit saat diaplikasikan. Hasil pengukuran menunjukkan bahwa tidak semua formula memenuhi syarat keamanan $\mathrm{pH}$ kulit tetapi semua formula memenuhi syarat $\mathrm{pH}$ menurut SNI.
Salah satu parameter kestabilan sediaan emulsi adalah pergeseran viscositas. Nilai respon pergeseran viskositas yang besar akan menandakan adanya ketidakstabilan sediaan selama penyimpanan. Jika nilai respon pergeseran viskositas dari suatu formula emulsi semakin besar maka semakin buruk stabilitas fisik dari formula tersebut. Dalam penelitian, respon pergeseran viscositas diwakili oleh selisih Rata-Rata Viscositas (mP.as) sebelum dan sesudah penyimpanan dipercepat. Pada formula I dan Formula II menunjukkan adanya penurunan respon pergeseran viskositas ketika tween 80 semakin sedikit. Semakin besar konsentrasi Tween 80 maka semakin menurun pula respon pergeseran viskositasnya.

Pada pengujian tipe emulsi dan derajat pemisahan fase menunjukkan bahwa tidak terdapat perubahan tipe emulsi. Kestabilan ini disebabkan oleh rigiditas film antar muka yang dibentuk oleh emulgator yang digunakan dan viskositas fase luar (Saxena et al., 1997). Dari uji stabilitas fisik yang dilakukan terhadap basis emulsi, terpilih basis formula III yaitu basis dengan konsentrasi Tween 80 sebanyak 4,5\%. Basis emulsi inilah yang ditambah ekstrak lulur dengan variasi konsentrasi $0,5 \%, 1,0 \%$ dan $1,5 \%$.

Hasil uji aktivitas antioksidan H\& B Lotion dapat dilihat pada tabel 4 . Semakin besar konsentrasi ekstrak lulur tradisional dalam H\&B Lotion, maka nilai IC-50 nya semakin tinggi. Formula dengan kandungan ekstrak lulur tradisional $0,5 \%$ dan $1,0 \%$ memiliki daya antioksidan lemah, sedangkan formula yang memiliki kandungan esktrak lulur tradisional $1,5 \%$ dan formula yang mengandung vitamin E $1,0 \%$ memiliki daya antioksidan sedang 
Tabel 1

Data Aktivitas Antioksidan H \& B Lotion

\begin{tabular}{|c|c|c|}
\hline Perlakuan & $\begin{array}{c}\text { IC-50 } \\
(\text { mean } \pm \text { SD })\end{array}$ & $\begin{array}{c}\text { Kruskal } \\
\text { wallis Test } \\
\text { p-value }\end{array}$ \\
\hline Basis & $309,05 \pm 2,79$ & \multirow{5}{*}{0,012} \\
\hline Formula A & $218,03 \pm 1,70$ & \\
\hline Formula B & $173,47 \pm 4,82$ & \\
\hline Formula C & $134,78 \pm 4,06$ & \\
\hline $\begin{array}{l}\text { Vitamin E } \\
1,0 \%\end{array}$ & $133,65 \pm 2,14$ & \\
\hline
\end{tabular}

menunjukkan bahwa ada perbedaan ratarata $\mathrm{IC}_{50}$ tiap perlakuan. Post hock test yang dilakukan dengan Mann Whitney Test menunjukkan bahwa formula yang mengandung $\quad 1,5 \%$ esktrak lulur tradisional memiliki daya antioksidan yang sama dengan formula yang mengandung $1,0 \%$ vitamin $\mathrm{E}$ sebagai kontrol positif ( $\mathrm{p}$ value 0,827). Hasil aktivitas ekstrak lulur antioksidan yang merupakan campuran sama banyak dari 5 macam ekstrak ethanol dari bahan kunyit, temu giring, daun kemuning, kayu cendana dan kulit kayu manis tersebut, jika dibandingkan dengan penelitian yang dilakukan oleh Rachman, dkk, 2008 tentang aktivitas antioksidan ekstrak tunggal dan kombinasi dari tanaman Curcuma spp, terlihat ada interaksi sinergis diantara kelima ekstrak tersebut. Menurut Rachman, dkk, 2008, aktivitas antioksidan ekstrak methanolik Kunyit dan Temu giring masing-masing adalah 43,57 ppm dan 108,54 ppm dan jika dibandingkan dengan control positif yang digunakan, aktivitas antioksidan kedua ekstrak tersebut lebih rendah masingmasing 8 sampai dengan 10 kali kontrol positif, begitu juga mengenai penelitian yang dilakukan oleh Rohman, A dan Sugeng, R, 2005 tentang daya antioksidan daun Kemuning yang menyatakan bahwa daya antioksidannya lima belas kali lebih lemah dibanding dengan vitamin $\mathrm{E}$ sedangkan menurut hasil penelitian, hasil aktivitas antioksidan campuran ekstrak terhadap control positif adalah sebanding. Peningkatan aktivitas antioksidan disebabkan kombinasi kelima ekstrak dari sediaan dan adanya bahan tambahan minyak zaitun.

Uji dilakukan apakah sediaan memberikan proteksi terhadap cairan dalam hal ini adalah $\mathrm{KOH}$. Hasil uji proteksi menunjukkan bahwa semua formula $\mathrm{H} \& \mathrm{~B}$ lotion antioksidan ekstrak lulur tradisional baik memberikan daya proteksi terhadap $\mathrm{KOH}$ karena tidak terdapat noda merah pada kertas saring selama waktu 5 menit

Tabel 2

\section{Data Daya Proteksi H \& B Lotion}

\begin{tabular}{lcc}
\hline Perlakuan & $\begin{array}{c}\text { Daya Proteksi } \\
\text { (mean } \pm \mathrm{SD})\end{array}$ & $\begin{array}{c}\text { One way } \\
\text { anava test } \\
\text { p-value }\end{array}$ \\
\hline Basis & $12,00 \pm 8,89$ & \\
Formula A & $30,33 \pm 1,53$ & \\
Formula B & $32,00 \pm 3,61$ & 0,023 \\
Formula C & $27,67 \pm 8,50$ & \\
Vitamin E & $22,33 \pm 6,81$ & \\
$1,0 \%$ & & \\
\hline
\end{tabular}

Uji anava satu arah dilakukan terhadap data daya proteksi menunjukkan hasil bahwa ada perbedaan antara rata-rata daya proteksi tiap perlakuan. Akan tetapi ketika dilakukan Tuckey Test perbedaan daya proteksi hanya terdapat antara daya proteksi basis emulsi dengan formula A dan $\mathrm{B}$ (masing-masing $p$-value 0,040 dan 0,024) sedangkan antara formula $A$ dengan Formula $\mathrm{B}$ dan $\mathrm{C}$ tidak menghasilkan beda signifikan terhadap daya proteksi H\& B Lotion sehingga dapat disimpulkan bahwa perbedaan konsentrasi ekstrak lulur tradisional tidak 
berpengaruh terhadap daya proteksi dari produk $H \& B$ lotion.

Evaluasi keamanan kosmetik, salah satunya adalah uji iritasi. Iritasi adalah adalah gejala inflamasi yang terjadi pada kulit atau membran mukosa segera setelah perlakuan berkepanjangan atau berulang dengan menggunakan bahan kimia atau bahan lain. Iritasi kulit disebabkan oleh suatu bahan dapat terjadi pada setiap orang, tidak melibatkan sistem imun tubuh dan ada beberapa faktor-faktor yang memegang peranan seperti keadaan permukaan kulit, lamanya bahan bersentuhan dengan kulit, dan konsentrasi dari bahan. Setelah beberapa waktu, kulit akan mengering terasa nyeri, mengalami perdarahan, dan pecah-pecah. Kondisi ini dapat diakibatkan oleh emulgator, solven, asam, alkali, detergen. Begitu kontak dengan zat kimia yang menyebabkan kondisi tersebut dihentikan, kulit akan pulih seperti sedia kala. Gejala umum yang dapat terjadi jika terjadi iritasi seperti panas, disebabkan karena dilatasi pembuluh darah pada daerah yang terkena yang dapat dilihat dengan timbulnya kemerahan pada daerah kulit tersebut (eritema). Selain itu dapat juga menyebabkan terjadinya udema, yang dapat diamati dengan terjadinya perbesaran plasma yang membeku pada daerah yang terluka, dan dipercepat dengan adanya jaringan fibrosa yang menutupi daerah tersebut.

Uji iritasi dilakukan pada 16 orang sukarelawan, dengan masing- masing bahan uji terdiri dari 3-5 sukarelawan. Emulsi yang diuji yaitu brand $\mathrm{H} \& \mathrm{~B}$ lotion yang ada di pasaran, emulsi yang mengandung basis saja serta emulsi yang mengandung ekstrak lulur tradisional. Metode yang digunakan adalah uji tempel empat jam. Pertama-tama lengan kanan bagian atas sukarelawan dibersihkan kemudian bahan uji yang sudah menempel pada penutup ditempelkan selama 4 jam. Setelah 4 jam, kain penutup dibuka dan bilas dengan air. 40 menit kemudian dilakukan pengamatan pada area pengolesan apakah ada kemerahan, udem, terasa gatal. Kulit tempat aplikasi diamati pada $0,24,48$, dan 72 jam. Data diolah untuk memperoleh indeks iritasi primer kulit (primary iriation index) dan respon dari iritasi dikategorikan.

Hasil uji iritasi $\mathrm{H}$ \& $\mathrm{B}$ lotion ekstrak lulur tradisional berdasarkan adalah hasil indeks iritasi primer yaitu 0 0,375, sedangkan basis $\mathrm{H}$ \& $\mathrm{B}$ lotion menunjukkan indeks iritasi primer 0,167 dan $\mathrm{H}$ \& $\mathrm{B}$ lotion branded yang ada di pasaran yang digunakan sebagai pembanding menunjukkan indeks iritasi primer 0,333. Hasil tersebut termasuk dalam kategori tidak berarti sehingga aman dalam penggunaannya.

Peneliti membagikan kuisioner pada 19 panelis yang melakukan analisis menurut uji kesukaan (parameter aroma, warna, homogenitas, kekentalan, kehalusan, kemudahan menyebar, kemudahan menyerap, kesan lembut, kesan lengket di kulit).

Hasil Friedman test terhadap data masing-masing parameter sensori menunjukkan bahwa perbedaan konsentrasi ekstrak lulur tradisional hanya berpengarug terhadap parameter sensori aroma H\& B Lotion. Hasil uji Wilcoxon unuk kesan aroma menunjukkan perbedaan bermakna pada hasil penilaian aroma Formula A dengan Formula B dan Formula $\mathrm{C}$ serta tidak ada perbedaan bermakna pada hasil penilaian aroma Formula B dengan Formula C.

Hasil rata-rata penilaian dari seluruh parameter sensori tersebut ketika 
diuji dengan anava satu arah menghasilkan $\mathrm{p}$ value $=0,562(>\operatorname{sig}=$ $0,05)$ sehingga dapat dikatakan penilaian secara keseluruhan terhadap ketiga formula tidak memiliki perbedaan bermakna sehingga untuk menilai keunggulan dari masing-masing formula akan lebih baik jika dilihat dari masingmasing parameter yang dihasilkan di mana formula B lebih unggul di tujuh parameter dari kesembilan parameter yang diuji jika dibanding dengan ketiga formula yang lain.

\section{KESIMPULAN DAN SARAN}

Kesimpulan dari hasil penelitian ini adalah :a) Tween 80 dengan konsentrasi $4,5 \%$ digunakan dalam basis emulsi, b)Perbedaan konsentrasi ekstrak lulur tradisional dalam $H \& B$ Lotion berpengaruh nyata terhadap khasiat antioksidannya dan konsentrasi yang memiliki daya antioksidan terbaik adalah $1,5 \%$. c) Perbedaan konsentrasi ekstrak lulur tradisional tidak berpengaruh terhadap daya proteksi dan keamanan dari produk karena semua konsentrasi mempunyai daya proteksi dan keamanan yang baik. d) Perbedaan konsentrasi ekstrak hanya berpengaruh terhadap parameter sensori aroma pada hasil uji hedonik dimana produk terbaik berdasarkan penilaian uji hedonik adalah $H \& B$ lotion dengan kandungan esktrak $1,0 \%$.

\section{DAFTAR RUJUKAN}

Anonim, 1995, Farmakope Indonesia Edisi IV, Jakarta, Departemen Kesehatan Republik Indonesia

Felicia.N, 2011, Rahasia Cantik Para Puteri : Mangir, Tapel dan, Bedak Dingin,http://female.kompas.com/r ahasia.cantik.para.puteri.mangir.ta pel.dan. bedak.dingin.com, diakses 15 September 2014.

Rachman F, Logawa ED, Hegartika H, Simanjuntak P, 2008, Aktivitas antioksidan Ekstrak Tunggal dan Kombinasinya dari Tanaman Curcuma sp. Jurnal, Ilmu Kefarmasian Indonesia, vol 6 No.2, 69-74.

Raymond C, dkk, 2009, Hand Book of Pharmaceutical Excipients, 6th Edition, USA: Pharmaceuticals Press and The American Pharmacist Association.

Rohman, A dan Sugeng R, 2005 Daya antioksidan ekstrak etanol Daun Kemuning (Murraya paniculata (L) Jack) secara in vitro, jurnal. Majalah Ilmu Kefarmasian, 16 (3), $136-140$.

Rowe, dkk, 2005, Hand Book of Pharmaceutical Excipients, USA: Pharmaceuticals Press and The American Pharmacist Association.

Tranggono, IR , Latifah, 2007, Buku Pegangan Ilmu Pengetahuan Kosmetika, Jakarta, PT. Gramedia Pustaka Utama

Vanukupal, 2012, Pelbagai kegunaan Kayu Cendana, http://majalahkesehatan.com, searching tanggal 15 Sepetember 2014. 